\title{
SILIK Syndrome: Should It Get a Special Concern in our Diagnostic Systems?
}

\author{
Dr. Hemanta Dutta ${ }^{1}$, Dr. Soumik Sengupta ${ }^{2}$
}

\section{ABSTRACT}

Background: Somatoform disorder is characterized by repeated presentations of physical symptoms, together with persistent requests for medical investigations, in spite of repeated negative findings and reassurances by doctors that the symptoms have no physical basis. Concept of SILIK syndrome has been derived from various patients who presents with a specific set of unspecified somatic symptoms.

Aims: To assess the prevalence and socio-demographic profiles of patients presenting with a set of unspecific somatic symptoms i.e SILIK sensation

Settings and design: the study was conducted in LGB Regional Institute of Mental Health. Total number of files of patients was 9232, which were analyzed in the period of $1^{\text {st }}$ April/2014 to $31^{\text {st }}$ March/2015.

Methods: Patients are generally diagnosed by using ICD 10 criteria. The medical records of total Out Patient Department (OPD) patients attending to our OPD from $1^{\text {st }}$ April/2014 to $31^{\text {st }}$ March/2015 were reviewed and the file records of the patients who were diagnosed to be a case of undifferentiated somatoform disorder are selected. From the selected file records of the patients, who complained of SILIK sensation are taken for the study. Socio demographic data are recorded from the files.

Results: Among 9232 patients 21\% (total number-1982) suffered from a specific set of unspecified somatic symptoms which was termed as SILIK syndrome.

Conclusion: A significant fraction of the patients attend our OPD with SILIK syndrome, who were still placed in inappropriate category of diagnostic system due to lack of proper dignognostic labeling. This study throws its light on these sections of the patients so that this syndrome can make its own stand in our diagnostic system.

Keywords: SILIK syndrome, somatoform disorder, socioeconomic status

\footnotetext{
${ }^{1}$ MBBS, M.D (Psychiatry), Senior resident, Department of Psychiatry, LGB regional Institute of Mental Health, Tezpur, Assam, India

${ }^{2}$ MBBS, M.D (Psychiatry) Assistant professor, Department of Psychiatry, LGB regional Institute of Mental Health, Tezpur, Assam, India

(C) 2015 I H Dutta, S Sengupta; licensee IJIP. This is an Open Access Research distributed under the terms of the Creative Commons Attribution License (http://creativecommons.org/licenses/by/2.0), which permits unrestricted use, distribution, and reproduction in any Medium, provided the original work is properly cited.
} 
Somatoform disorder is characterized by repeated presentations of physical symptoms, together with persistent requests for medical investigations, in spite of repeated negative findings and reassurances by doctors that the symptoms have no physical basis. ${ }^{1,2}$ It comprises of various categories like somatisation disorder, undifferentiated somatoform disorder, somatoform autonomic dysfunction, persistent somatoform pain disorder etc. ${ }^{2}$ According to ICD 10, when somatic complains are multiple, varying and persistent, but the complete and typical clinical picture of somatization disorder is not fulfilled, the diagnosis of undifferentiated somatoform disorder ought to be considered. ${ }^{2}$ Our institute is a regional institute in the north eastern region which is situated at Tezpur, Assam. It serves the patients who come from various districts of Assam along with neighboring states like West Bengal, Nagaland and Arunachal Pradesh etc. A group of patients come to our institute with a specific set of somatic symptoms. Especially as they complain of either piercing pain in the head or burning and hot sensation of the head, or wave like sensation in head. They generally term this problem as SILIK sensation. While enquiring about the actual literal meaning of the term SILIK, we could discover a term "Siringoni" in Assamese dictionary with similar meaning. ${ }^{3}$ So we have landed at a conclusion that the term SILIK has been most probably derived from it. Many of those patients fail to fulfill the proper criteria of somatoform disorder. So we used to put them under undifferentiated somatoform disorder category. In our study, we have endeavored to analyze the actual statistics of the patients complaining of SILIK sensation, so that it can stand on its way to hold a special category in our future diagnostic systems.

\section{METHODOLOGY:}

Study area: The study was conducted in Lokoprio Gopinath Bordoloi Regional Institute of Mental Health (LGBRIMH), Tezpur, Assam.

The design of the study: Patients are generally diagnosed by using ICD 10 criteria. The medical records of total Out Patient Department (OPD ) patients attending to our OPD from $1^{\text {st }}$ April/2014 to $31^{\text {st }}$ March/2015 were reviewed and the file records of the patients who were diagnosed to be a case of undifferentiated somatoform disorder are selected. From the selected file records of the patients, who complained of SILIK sensation are taken for the study. Socio demographic data are recorded from the files.

\section{Schematic presentation of the design of the study}

Total patients attended from 1st April/2014 to 31 ${ }^{\text {st }}$ March/2015

Total diagnosed cases of undifferentiated somatoform disorder

Total cases complaining of SILIK sensation 
Inclusion criteria: Both male and female patients with diagnosis of undifferentiated somatoform disorder of all age groups.

Exclusion criteria: Cases apart from undifferentiated somatoform disorders were excluded from the study.

Tools used in the study: No definite diagnostic tools are required to gather information in our subject area; however ICD10 criteria’s were strictly followed while diagnosing the cases.

All other information's are gathered from the file records of the patients.

\section{Statistical analysis:}

The information has been analyzed using statistical software packages like SPSS and XLSTAT.

\section{RESULTS}

During analysis it has been revealed that total number of patients who attended our OPD were 9232. Among them, 3591 patients (38\%) were diagnosed to be case of somatoform disorder. $30 \%$ of patients \{total number 2833\} were diagnosed to be a case of undifferentiated somatoform disorder. Among them, 21 \% of the study population (total number - 1982) complained of SILIK sensation.

Our study has shown that $57 \%$ of the population is from the age group of $41-50$ years, followed by $34.7 \%$ of population from age group of 51-60 years. The results have been shown in the table 1 and figure1.

Table 1: Table showing age distribution of the study group

\begin{tabular}{|c|c|c|c|c|c|c|c|}
\hline & \multicolumn{3}{|c|}{ Sex } & & \multirow{2}{*}{ Total } & \multirow{2}{*}{$\begin{array}{l}\text { Total } \\
\%\end{array}$} \\
\hline & & Male & $\%$ & Female & $\%$ & & \\
\hline \multirow{5}{*}{$\begin{array}{l}\text { Age } \\
\text { groups }\end{array}$} & $21-30$ & 0 & 0 & 29 & 1.4 & 29 & 1.4 \\
\hline & $31-40$ & 0 & 0 & 33 & 1.6 & 33 & 1.6 \\
\hline & $41-50$ & 60 & 3 & 1075 & 54.2 & 1135 & 57 \\
\hline & $51-60$ & 5 & 0.25 & 684 & 34.5 & 689 & 34.7 \\
\hline & $61-70$ & 1 & 0.05 & 95 & 4.7 & 96 & 4.8 \\
\hline \multicolumn{2}{|l|}{ Total } & 66 & 0.30 & 1916 & 96.7 & 1982 & 100 \\
\hline
\end{tabular}




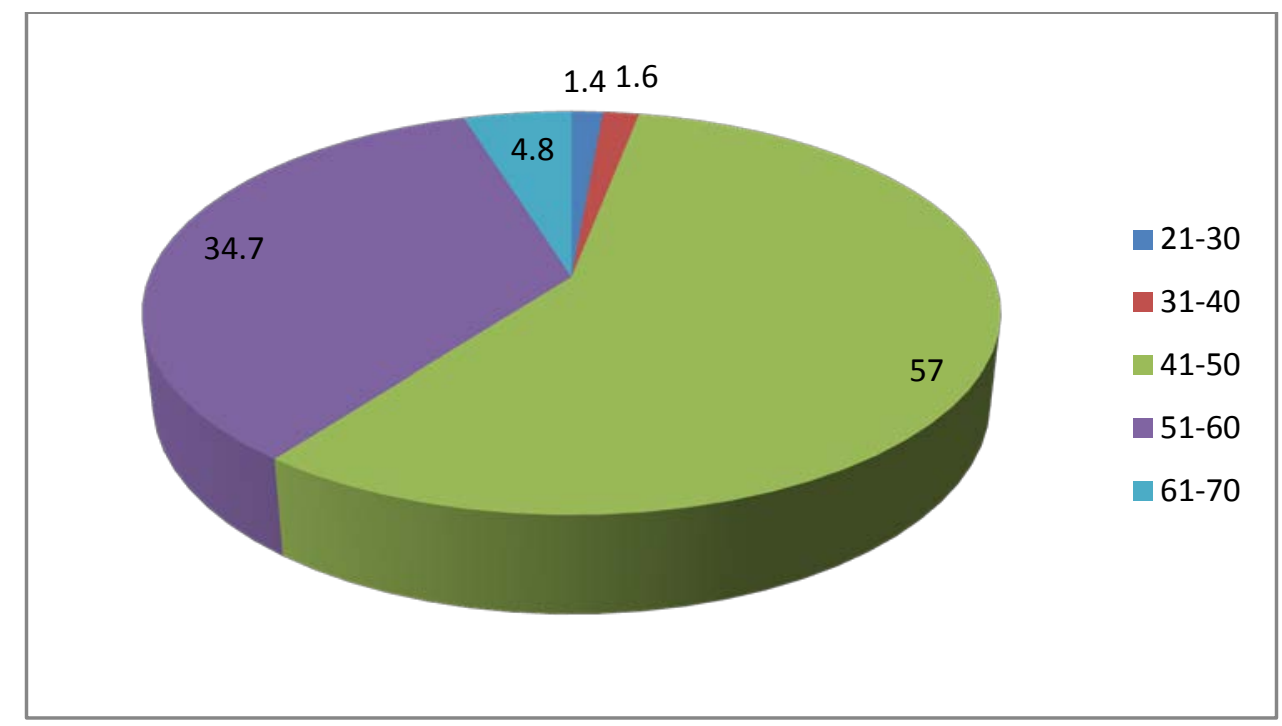

Figure 1: Figure showing distribution of age group of the study group.

While observing the statistics of influence of religion we observed that $96.2 \%$ of the population belongs to Muslim community, in contrast to that only 3.5\% of the population were from Hindu community. The results have been portrayed through table 2 and figure 2 .

Table 2: Table showing distribution of religious group of the study group

\begin{tabular}{|l|l|l|l|l|l|l|l|}
\hline \multicolumn{2}{|c|}{} & \multicolumn{3}{c|}{ Sex } & & & \multicolumn{1}{|c|}{ Total } \\
\cline { 3 - 9 } & Male & $\%$ & Female & $\%$ & Total & \% \\
\hline \multirow{3}{*}{ Religion } & Hindu & 8 & 0.40 & 63 & 3.18 & 71 & 3.58 \\
\cline { 2 - 9 } & Muslim & 58 & 2.92 & 1850 & 93.34 & 1908 & 96.27 \\
\cline { 2 - 9 } & Christian & 0 & 0 & 3 & 0.15 & 3 & 0.15 \\
\hline Total & 66 & 3.33 & 1916 & 96.67 & 1982 & 100 \\
\hline
\end{tabular}

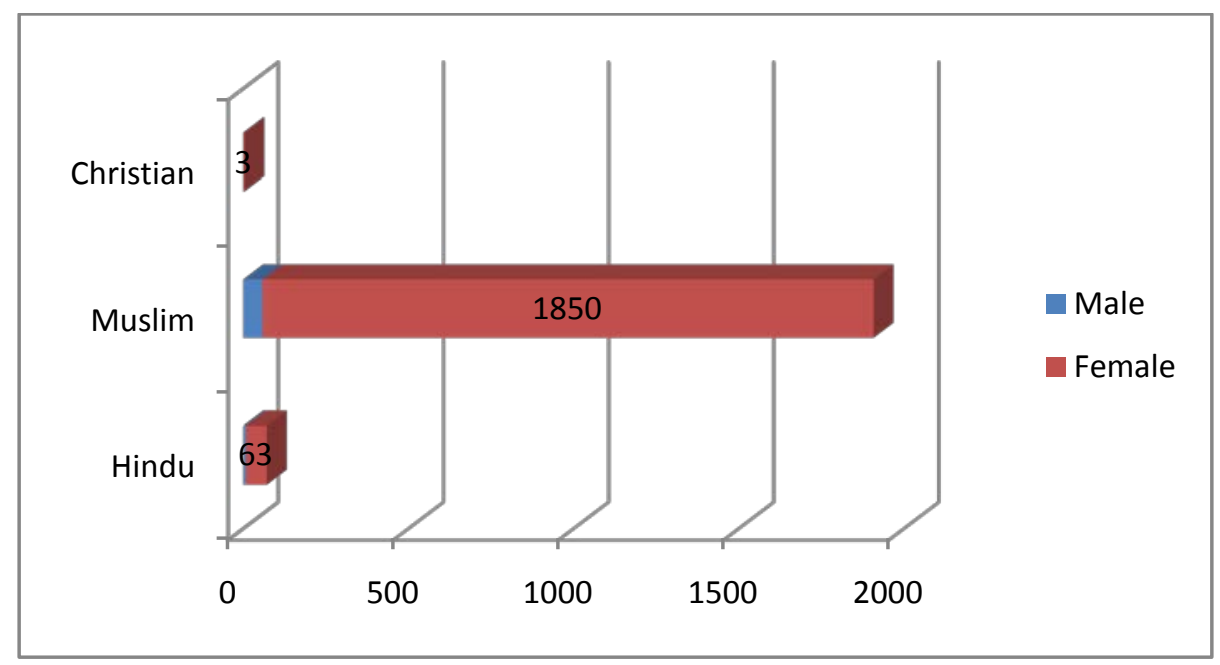

Figure 2: Figure showing distribution of religious groups of the study group. 
Statistical analysis has revealed that majority (97.4\%) of our study population were married against $2.52 \%$ of unmarried population. Table 3 and figure 3 have demonstrated the distribution of the marital status of the study group.

Table 3: Table showing distribution of marital status of the study group

\begin{tabular}{|l|l|l|l|l|l|l|l|}
\hline \multicolumn{2}{|c|}{} & \multicolumn{3}{|c|}{ Sex } & & & Total \\
\cline { 3 - 5 } & Male & $\%$ & Female & \% & Total & $\%$ \\
\hline \multirow{2}{*}{$\begin{array}{l}\text { Marital } \\
\text { status }\end{array}$} & Unmarried & 14 & 0.71 & 36 & 1.82 & 50 & 2.52 \\
\cline { 2 - 5 } & Married & 52 & 2.62 & 1880 & 94.85 & 1932 & 97.48 \\
\hline Total & 66 & 3.33 & 1916 & 96.67 & 1982 & 100 \\
\hline
\end{tabular}

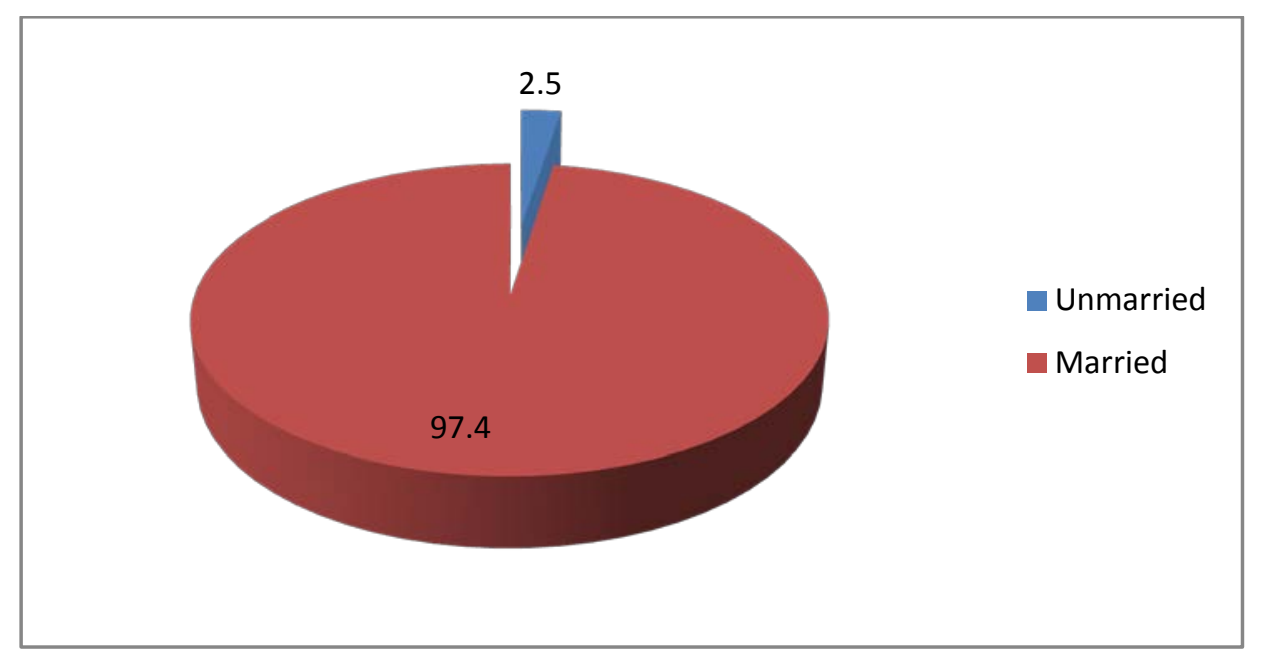

Figure 3: Figure showing distribution of marital status of the study group.

In terms of locality, 98.64\% of the study population was from rural areas of Assam, while only $1.36 \%$ of the population was from semi urban areas. No one from our study subjects were from urban areas of the state. Table 4 and figure 4 have demonstrated the results.

Table 4: Table showing distribution of locality of the study group

\begin{tabular}{|c|c|c|c|c|c|c|c|}
\hline & \multicolumn{3}{|c|}{ Sex } & \multirow[b]{2}{*}{$\%$} & \multirow[b]{2}{*}{ Total } & \multirow{2}{*}{$\begin{array}{l}\text { Total } \\
\%\end{array}$} \\
\hline & & Male & $\%$ & Female & & & \\
\hline \multirow[t]{3}{*}{ Locality } & Rural & 62 & 3.12 & 1893 & 95.5 & 1955 & 98.64 \\
\hline & $\begin{array}{l}\text { Semi- } \\
\text { urban }\end{array}$ & 4 & 0.2 & 23 & 1.17 & 27 & 1.36 \\
\hline & Urban & 0 & 0 & 0 & 0 & 0 & 0 \\
\hline \multicolumn{2}{|l|}{ Total } & 66 & 3.32 & 1916 & 96.67 & 1982 & 100 \\
\hline
\end{tabular}


SILIK Syndrome: Should It Get a Special Concern in our Diagnostic Systems?

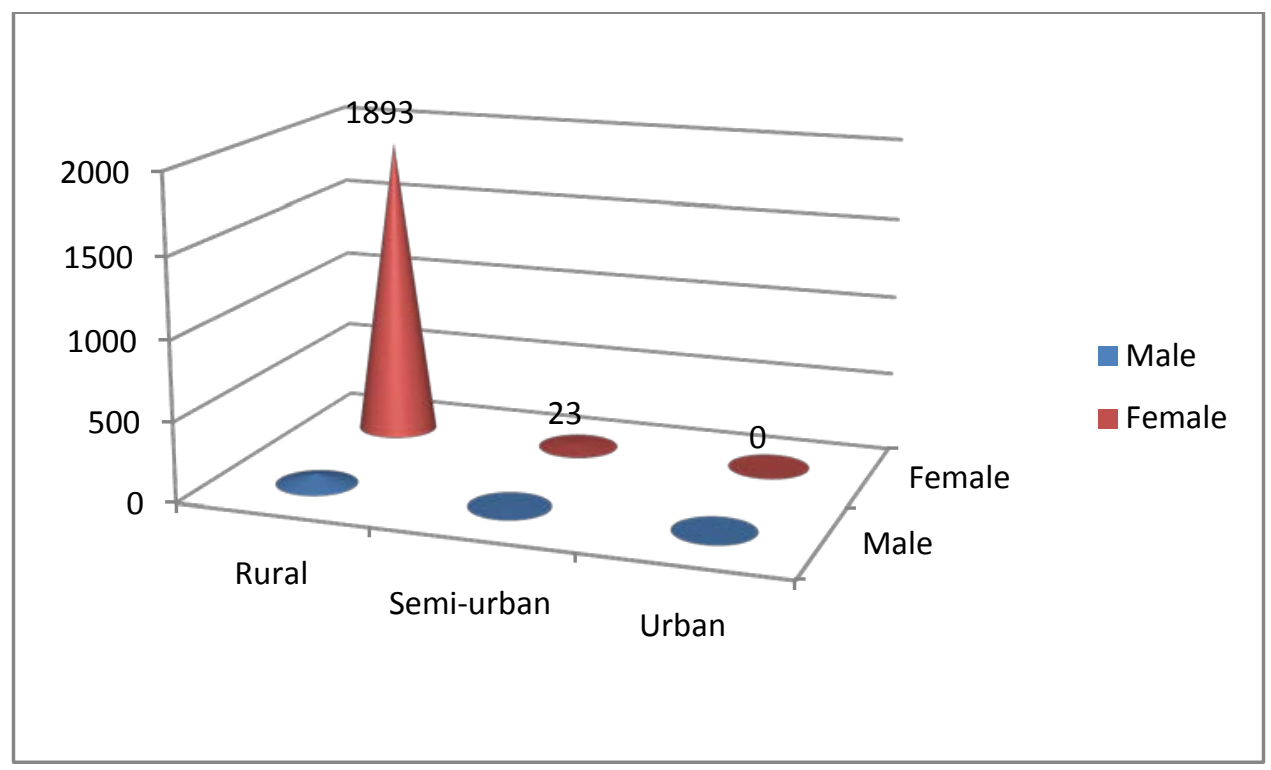

Figure 4: Figure showing distribution of locality of the study group.

$94.2 \%$ of the study subjects were illiterate and 5.8\% were educated up to primary school certificate. But no one from our study groups was educated beyond primary school level. The results have been shown in the table 5 and figure 5 .

Table 5: Table showing distribution of educational status of the study group

\begin{tabular}{|c|c|c|c|c|c|c|c|}
\hline & \multicolumn{3}{|l|}{ Sex } & \multirow[t]{2}{*}{$\%$} & \multirow[t]{2}{*}{ Total } & \multirow{2}{*}{$\begin{array}{l}\text { Total } \\
(\%)\end{array}$} \\
\hline & & Male & $\%$ & Female & & & \\
\hline \multirow[t]{5}{*}{ Education } & Illiterate & 36 & 1.87 & 1831 & 92.39 & 1867 & 94.2 \\
\hline & Primary school certificate & 30 & 1.51 & 85 & 4.29 & 115 & 5.8 \\
\hline & Middle school certificate & 0 & 0 & 0 & 0 & 0 & 0 \\
\hline & High school certificate & 0 & 0 & 0 & 0 & 0 & 0 \\
\hline & Graduate or post graduate & 0 & 0 & 0 & 0 & 0 & 0 \\
\hline \multicolumn{2}{|l|}{ Total } & 66 & 3.33 & 1916 & 96.68 & 1982 & 100 \\
\hline
\end{tabular}


SILIK Syndrome: Should It Get a Special Concern in our Diagnostic Systems?

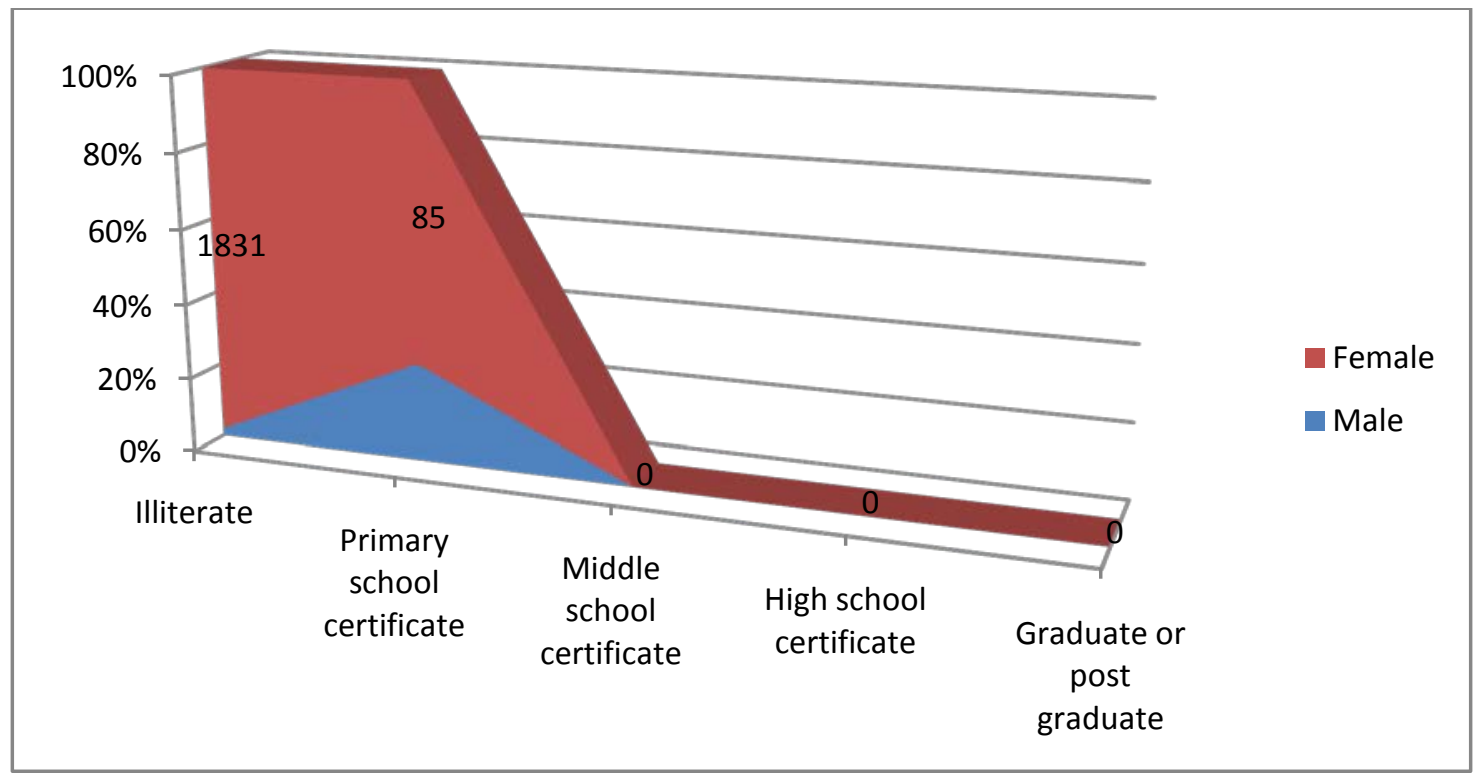

Figure 5: Figure showing distribution of educational status of the study group.

While studying the socio economic status of our study group, we observed that $99 \%$ of our study group belongs to lower socio economic class. Only $0.95 \%$ of the study group was from upper lower class. Results of analysis socio economic status of our study group have been shown in the table 6 and figure 6.

Table 6: Table showing distribution of socio economic status of the study group

\begin{tabular}{|c|c|c|c|c|c|c|c|}
\hline & \multicolumn{3}{|c|}{ Sex } & & \multirow[b]{2}{*}{ Total } & \multirow{2}{*}{$\begin{array}{l}\text { Total } \\
(\%)\end{array}$} \\
\hline & & Male & $\%$ & Female & $\%$ & & \\
\hline \multirow{5}{*}{$\begin{array}{l}\text { Socio- } \\
\text { economic } \\
\text { status }\end{array}$} & Upper(I) & 0 & 0 & 0 & 0 & 0 & 0 \\
\hline & $\begin{array}{l}\text { Upper } \\
\text { middle(II) }\end{array}$ & 0 & 0 & 0 & 0 & 0 & 0 \\
\hline & $\begin{array}{l}\text { Lower } \\
\text { middle(III) }\end{array}$ & 0 & 0 & 0 & 0 & 0 & 0 \\
\hline & $\begin{array}{l}\text { Upper } \\
\text { Lower(IV) }\end{array}$ & 13 & 0.65 & 6 & 0.3 & 19 & 0.96 \\
\hline & Lower(v) & 53 & 2.67 & 1910 & 96.36 & 1963 & 99.04 \\
\hline \multicolumn{2}{|l|}{ Total } & 66 & 3.33 & 1916 & 96.67 & 1982 & 100 \\
\hline
\end{tabular}




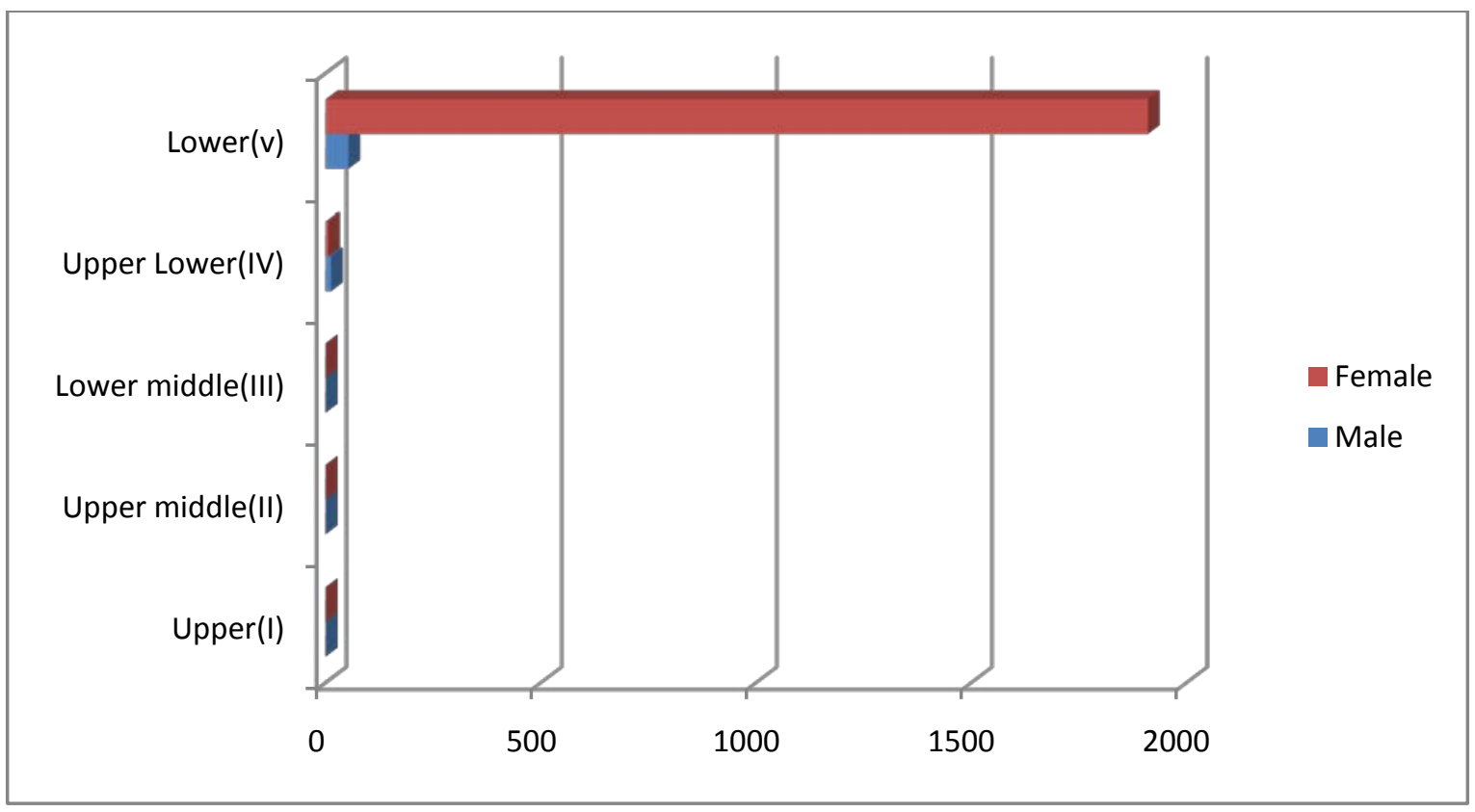

Figure 5: Figure showing distribution of socio- economic status of the study group.

\section{DISCUSSION:}

Our study group has demonstrated similar findings in term of socio-demographic profiles of somatoform disorder. In terms of prevalence, $21 \%$ of our study population has been found to be having SILIK sensation which is similar to the prevalence rate of somatoform disorder as reported by de Waal et al and Hilderink et al. ${ }^{4,5}$ In our study area females are seen to be suffering more form somatic problems than the male group, which is also in accordance with earlier studies. ${ }^{1,6,7}$ In terms of age, generally somatoform disorder has been found in the $3^{\text {rd }}$ decade but in case of our study population major fraction (54\%) belongs to $41-50$ age group. ${ }^{1}$ In case of marital status it has been observed that married population has suffered more from the unspecified somatic symptom syndrome. Our study group has shown similar types of results like previous reports in terms of socio economic and educational status i.e. SILIK sensation has been found to be more common in less educated and low socioeconomic group. ${ }^{1,8}$ In terms of locality status, our results have demonstrated that persons with SILIK sensations are more likely from rural areas. Similar studies in this regard could not be found which were searched manually and through web. Purpose of our study is to highlight this uncommon syndrome which comprises of multiple unspecific symptoms, which were shown by majority of the patients attending to our OPD settings. Due to lack of proper diagnostic labeling, we try to fit them under undifferentiated somatoform disorder as they could not fulfill the proper criteria of somatisation disorder. Strength of our study was the sample size. A large size sample has given us the opportunity to arrive at conclusive results. Limitation of our study is its type itself, as our study is a retrospective one there was a possibility of missing some important information. However, our study has a unique value as no similar reports and concept of this syndrome has been provided by any study report till yet. We recommend a well designed study in a large scale to demonstrate 
the rising prevalence of this syndrome so that it can make a unique stand under the category of somatoform disorder.

\section{REFERENCE}

Baruah, B. Retrieved August 8, 2015, from http://www.xobdo.org/\#

Chadda, R. (2008). Somatoform disorder. In Textbook of Postgraduate Psychiatry (2nd ed., Vol. 1, pp. 280-289). New Delhi, New Delhi: Jaypee Brothers Medical (P).

DeGruy, F., Columbia, L., \& Dickinson, P. (1987). Somatization disorder in a family practice. J Fam Pract, 25(1), 45-51.

Diagnostic and statistical manual of mental disorders: DSM-IV-TR. (4th ed.). (2000). Washington, DC: American Psychiatric Association.

Hilderink, P., Collard, R., Rosmalen, J., \& Voshaar, R. (n.d.). Prevalence of somatoform disorders and medically unexplained symptoms in old age populations in comparison with younger age groups: A systematic review. Ageing Research Reviews, 151-156.

Ltchstein, P. (1986). Caring for the Patient With Multiple Somatic Complaints. Southern Medical Journal, 310-314.

The ICD-10 classification of mental and behavioural disorders: Clinical descriptions and diagnostic guidelines. (10th ed.). (1992). Geneva: World Health Organization.

Waal, M., Arnold, I., Eekhof, J., \& Hemert, A. (2004). Somatoform disorders in general practice: Prevalence, functional impairment and comorbidity with anxiety and depressive disorders. The British Journal of Psychiatry, 470-476. 